\title{
Population, Poverty, and Climate Change
}

Monica Das Gupta

This literature review focuses on the relationships between population, poverty, and climate change. Developed countries are largely responsible for global warming, but the brunt of the fallout will be borne by developing countries in forms such as lower agricultural output, poorer health, and more frequent natural disasters. Although carbon emissions per capita have leveled off in developed countries, they are projected to rise rapidly in developing countries because of economic growth and population growth. Unfortunately, the latter will rise most notably in the poorest countries, combining with climate change to slow poverty reduction. These countries have many incentives to lower fertility. Previous studies indicate that in high fertility settings, fertility decline facilitates economic growth and poverty reduction. It also reduces the pressure on livelihoods and frees resources that can be used to cope with climate change. Moreover, slowing population growth helps avert some of the projected global warming, which will benefit the poorest countries far more than it will benefit developed countries that lie at higher latitudes and/or have more resources to cope with climate change. Natural experiments indicate that family-planning programs are effective and highly pro-poor in their impact. While the rest of the world wrestles with the complexities of reducing emissions, the poorest countries will benefit from simple programs to lower fertility. Population, Poverty, Economic growth, Climate change, Global warming, Family planning, sub-Saharan Africa, Developed countries, Developing countries, Public policy, Sustainable development, Ecological injustice JEL codes: Q56, Q54, J13, J18

The relationships among population dynamics, poverty, and climate change are now recognized in the literature on sustainable development. This paper summarizes the evidence currently available on these relationships and their implications for the poorest developing countries. The paper begins with a review of the 
literature on population growth and the depletion of natural resources. This relationship has been much debated, with some arguing that human innovation can overcome any natural resource constraint. The consensus now is that although this may apply to resources that are more fully priced, it is much more difficult to manage environmental common property resources. Efforts to price the use of such resources, notably by imposing a carbon tax, have so far met with very limited success.

The literature indicates that there is considerable "ecological injustice" between developed and developing countries. Although developed countries have generated most of the current stock of emissions that cause global warming, the brunt of the burden will be borne by developing countries. These burdens are reviewed in Section 2. Section 3 reviews the gains to the poorest countries from fertility decline, which facilitates economic growth and poverty reduction, helps mitigate the burdens of climate change that they face, and reduces future increases in global warming that will disproportionately affect these countries. Section 4 reviews the evidence on the effectiveness of family-planning programs in helping to reduce fertility. Natural experiments indicate that these programs are effective and have a strong pro-poor impact.

The paper concludes that while the rest of the world wrestles with the political and technological problems of reducing emissions, the poorest countries have available a simple and effective means of using family-planning programs to improve their circumstances.

\section{Population and Natural Resources}

The publication of the study Limits to Growth (Meadows et al. 1972) caused considerable controversy. It summarized the historical trajectory from 1900 to 1970 of non-renewable natural resources, pollution, population size, food production, and industrial output and simulated their trajectory from 1970 to 2100 . The study concluded that sustainable development could not be achieved without curtailing population growth and the use of natural resources.

Others have argued that more rapid population growth may help drive economic growth by spurring technological innovation that can potentially stretch resources indefinitely. For example, Boserup (1965) argued that population growth helps induce agricultural innovation and agricultural intensification, allowing greater productivity per unit of land to feed the larger population. Similarly, Simon (1981, 1996) argued that people and markets innovate in response to potential resource shortages, and therefore the resource base is effectively infinite. ${ }^{1}$

Simon's arguments were supported by studies of the costs of some industrial resources, which were found to have fallen sharply between 1870 and 1957, a period 
during which there was rapid growth in both population and industrial output (Potter and Christy 1962; Barnett and Morse 1963). There are strong private incentives to find innovative ways of managing the use of such clearly priced resources to keep prices down.

The concerns raised by studies forecasting resource depletion receded quickly as technological innovation rapidly increased agricultural productivity and kept the prices of some commodities down. However, these innovations have had a much smaller effect on reducing the depletion of environmental common property resources.

\section{The Complexities of Managing Environmental Common Property Resources}

Recently, widespread concern over environmental common property resources has again raised issues of sustainable development.

A driving need for continuing adaptation and innovation is generated by the world's growing consumption needs, which are associated with increases in percapita consumption levels and population growth. Technological progress has certainly increased production, but this has not been without negative ramifications. Common property resources are under pressure from activity to meet rising consumption requirements. For example, increasing agricultural production per acre through the higher use of chemicals and fertilizers has been very effective at raising food production, but it has also increased fertilizer runoff, thereby creating lowoxygen "dead zones" in coastal oceans (Map 1).

While market forces provide incentives to find ways to better manage the use of non-renewable resources that are clearly priced, it is proving more difficult to conserve resources that are unpriced or underpriced, such as oceans and the atmosphere. Even understanding the intricacies of environmental change is a challenging task for scientists, and organizing collective action to avert negative consequences is a challenging task for political leaders even at local levels, let alone at national and global levels.

These factors combine to create a daunting list of necessary adaptations and innovations, which are complex to develop and to implement. The World Development Report 2010 summarizes some of the measures needed for sustainable food production (World Bank 2010). To manage land and water resources to feed growing populations and protect natural systems, this report notes the need for politically daunting measures, such as the following:

- building flexible international agreements;

- pricing carbon, food, and energy;

- redirecting agricultural subsidies; and

- strengthening the policy environment for natural resource management. 
Map 1. Intensive Agriculture in Developed Countries has Contributed to the Proliferation of Dead Zones in Coastal Areas

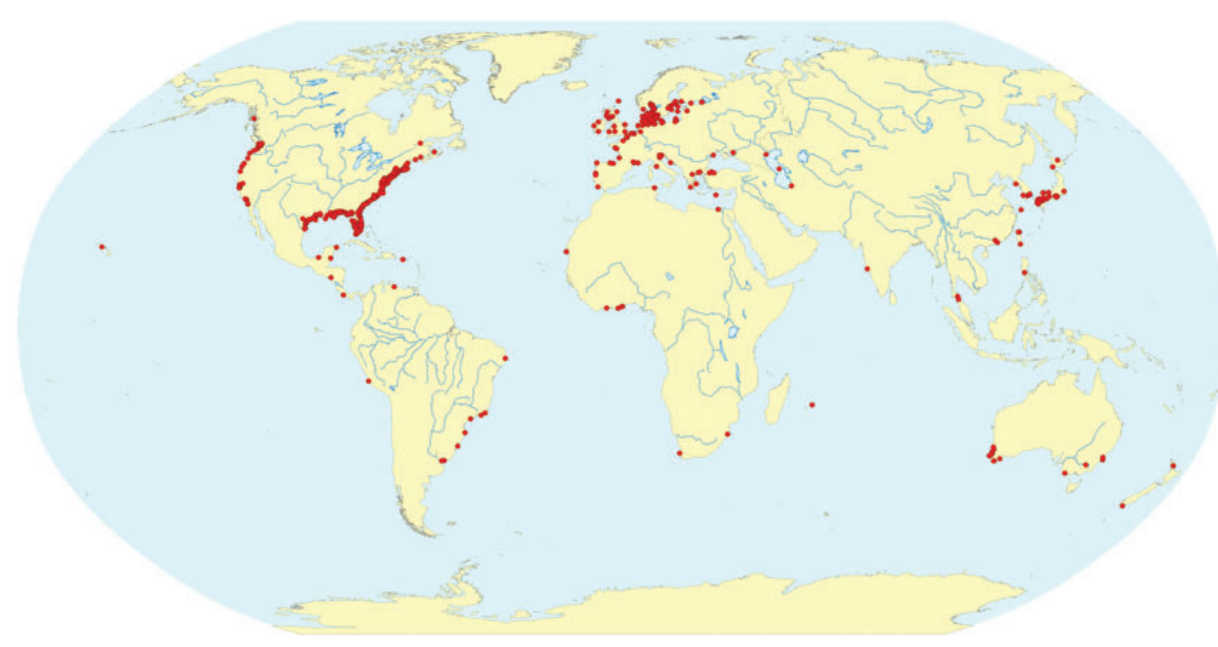

Source: World Bank (2010), World Development Report 2010: Map 3.4 (derived from Diaz and Rosenberg 2008). Explanatory note from the original figure in WDR 2010: "In the developed world intensive agriculture has often come at high environmental cost, including runoff of excess fertilizers leading to dead zones in coastal areas. Dead zones are defined as extreme hypoxic zones, that is, areas where oxygen concentrations are lower than 0.5 milliliters of oxygen per liter of water. These conditions normally lead to mass mortality of sea organisms, although in some of these zones organisms have been found that can survive at oxygen levels of 0.1 milliliter per liter of water".

Conventional estimates of growth in Gross Domestic Product (GDP) are misleading on the sustainability of production possibilities because they ignore the depreciation of natural capital (Arrow et al. 2004; Dasgupta 2010).

"Since GDP is the total value of the final goods and services an economy produces, it does not deduct the depreciation of capital that accompanies production - in particular, it does not deduct the depreciation of natural capital. In the quantitative models that appear in leading economics journals and textbooks, nature is taken to be a fixed, indestructible factor of production. The problem with the assumption is that it is wrong: nature consists of degradable resources. Agricultural land, forests, watersheds, fisheries, fresh water sources, river estuaries and the atmosphere are capital assets that are self-regenerative, but suffer from depletion or deterioration when they are over-used. ... To assume away the physical depreciation of capital assets is to draw a wrong picture of future production and consumption possibilities that are open to a society." (Dasgupta 2010, 6) 
Moreover, "property rights to natural capital are frequently unprotected or ill-specified. . ., (which) typically leads to their overexploitation, and so to waste and inequity" (Dasgupta 2010, 6).

Arrow et al. (2004, Table 2) estimate how much "genuine wealth per capita" (including natural capital, human capital, and manufactured capital) changed during 1970-2000. The estimates are necessarily approximate, but they have been made carefully, and the results are instructive. They find that although GDP per capita grew quite rapidly during 1970-2000 in all regions except sub-Saharan Africa, rates of growth in "genuine wealth per capita" were far lower. They declined sharply in sub-Saharan Africa and in the Middle East and North Africa (by $-2.6 \%$ and $-3.8 \%$ per year, respectively), and they grew very slowly (well below 1\% per year) in South Asia and the United States. They grew rapidly only in China because of its low population growth and heavy investment in productivity. Revising the method to include more information on growth in human capital and institutional change, Dasgupta (2010, 9-10) derives far lower estimates of growth in genuine wealth per capita for China 1970-2000, and for South Asia, he estimates a decline of between $-0.4 \%$ per year (India) and $-1.4 \%$ (Pakistan).

Human ingenuity has faced an uphill task in devising ways of managing common property resources given the institutional and political challenges in aligning divergent interests. Markets are very poor at incentivizing people not to overuse resources that are unpriced or under-priced relative to social cost (Arrow 1969; Dasgupta 2001; Stern 2006), especially in the case of transnational common resources (Dasgupta et al. 1997). The consequent negative externalities need to be addressed through collective action, but in the absence of strong mechanisms for mutual coercion and cooperation, it is very difficult to align the interests of different stakeholders to this end. Ostrom (1990) has argued that common property can be successfully managed by user associations in small communities if eight "design principles" are met, including the ability to effectively exclude unentitled parties. Such conditions clearly do not apply to global common resources. As Lee $(1990,317)$ notes, "Each birth inflicts costs on all others by reducing the value of their environmental birthright". 2

The juxtaposition of these scientific, executive, and political challenges places high demands on the ability of national and global institutions to respond to these challenges, as evidenced by the slow progress made in decades of efforts to regulate carbon emissions. The original projections of the Limits to Growth study for the 1970-2000 period correspond broadly with the observed trends during this period (Turner 2008, 2012).

\section{Managing Climate Change: Addressing Per-Capita Emissions and Population}

Models of climate change take population size into account, but they typically treat it as a given (for example, Stern 2006; Nordhaus 2008, 2012). They tend to use 
the United Nations medium variant population projections. Using this approach, the World Bank (2010, Figure 3.5) estimates the impact of climate change on the growth in agricultural productivity required to meet the world's rising food demand. The model incorporates projected rises in food demand due to growth in incomes as well as in population size and shows how much more difficult it will be to meet that demand given anticipated climate change. What is needed is a huge increase in agricultural productivity backed by greatly intensified regulation to protect natural systems.

However, as we discuss below, population size is amenable to policy, and it makes a significant difference to the size of adjustments required on other fronts. Models vary, but the World Bank (2010) estimates that to meet the growing demand for food between 2005 and 2055, agricultural productivity will need to rise by $64 \%$ under the assumptions of the "business-as-usual" scenario and by a further $80 \%$ to offset the projected stresses arising from climate change (Figure 1). However, the model indicates that if population remained constant at the 2005 level, agricultural productivity would need to rise only $25 \%$ under the "business-as-usual" scenario; that is, more of the required productivity increase under the "business-as-usual" scenario is necessitated by population growth than by increases in consumption per capita.

The developed countries' carbon emissions per capita are far higher than those of the developing countries, but the latter account for nearly all of the projected increase in emissions between now and 2050 (Stern 2006, Figure 7.3). Although emission rates in the developed countries seem to have peaked, they are growing rapidly in the developing countries due to both economic growth and population growth. Although China has had the steepest growth in carbon emissions with its high rate of economic growth, its estimated total emissions in 2008 were similar to those of other developing countries as a group (excluding India), ${ }^{3}$ partly because the latter had twice the population of China (UN 2013). GDP per capita is rising rapidly across developing countries, including sub-Saharan Africa in the 2000s (IMF 2010, 2011). Nearly all of the projected global population growth will occur in developing countries, whose population (excluding China and India) is projected to grow 2.7-fold between 2000 and 2100, driven largely by the six-fold increase projected for sub-Saharan Africa (UN 2013, medium variant). It is estimated that the effect of a $40 \%$ reduction in $\mathrm{CO}_{2}$ emissions per capita in developed countries between 2000 and 2050 would be entirely offset by the increase in emissions attributable to expected population growth in poorer countries over this period, even if we assume no change in emissions per capita in these countries (Dyson 2005). ${ }^{4}$

Managing global warming may require different policy approaches in different settings. Imposing a carbon tax is strongly recommended as the simplest way to reduce carbon emissions (Stern 2006; Nordhaus 2008, 2012). By putting a price on carbon emissions, such a tax creates incentives to conserve global common 
Figure 1. Required Growth in Agricultural Productivity Given Estimated Population Growth, Increase in Per Capita Consumption, and Climate Change

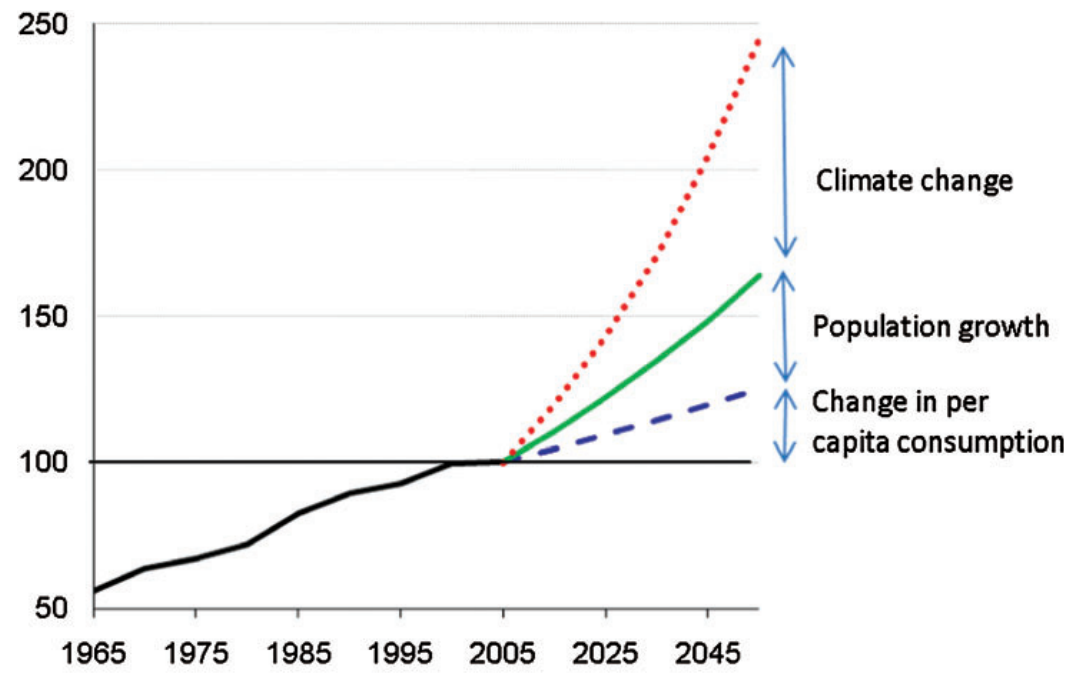

\section{.... The scenario with climate change \\ - The "business as usual" scenario without climate change \\ --- The "business as usual" scenario without climate change AND NO POPULATION GROWTH AFTER 2005}

Source: World Bank (2010) World Development Report 2010: Figure 3.5 (derived from Lotze-Campen et al. 2009). We thank Dr. Lotze-Campen for disaggregating the "business-as-usual" scenario into two estimates: (1) with population held constant at the 2005 level and (2) the WDR 2010's "business-as-usual" scenario, which includes anticipated population increase to 9 billion by 2055 .

Note: The original explanatory note said it was the required annual growth. Dr. Lotze-Campen corrected this by deleting the word "annual".

Explanatory note from the original figure in WDR 2010: "The figure shows the required growth in an agricultural productivity index under two scenarios. In this index, 100 indicates productivity in 2005. The projections include all major food and feed crops. The straight line represents a scenario without climate change of global population increasing to 9 billion in 2055; total calorie consumption per capita and the dietary share of animal calories increasing in proportion to rising per capita income from economic growth; further trade liberalization (doubling the share of agricultural trade in total production over the next 50 years); cropland continuing to grow at historical rates of 0.8 percent a year; and no climate change impacts. The dotted line represents a scenario of climate change impacts and associated societal responses (IPCC SRES A2): no CO2 fertilization, and agricultural trade reduced to 1995 levels (about 7 percent of total production) on the assumption that climate change-related price volatility triggers protectionism and that mitigation policy curbs the expansion of cropland (because of forest conservation activities) and increases demand for bioenergy (reaching 100 EJ [ $\left[10^{18}\right.$ joules] globally in 2055)”.

property resources while providing incentives and fiscal resources for developing cleaner technologies. However, some major polluters among the developed countries have shown a limited political appetite for this, and developing countries argue that such taxes will unfairly constrain their economic growth, with restrictions that 
the currently developed countries did not have to face when they were industrializing rapidly.

For countries that still have high levels of fertility, which typically are still poor and have very low per capita emission rates, the key approach seems to be to reduce fertility. Clearly, they do not owe it to the world to reduce fertility to help slow the pace of climate change. However, they have strong incentives of their own to reduce fertility, as discussed below.

\section{The Unequal Impact of Climate Change}

The developed countries are responsible for much of the accumulation of emissions that affect climate change because they began rapid industrialization by the end of the nineteenth century. However, in a twist of fate, the impact of climate change will be felt most sharply in the developing countries,. Many of these countries lack the financial resources for adaptation/mitigation efforts, and for some, the capacity to act may also be hindered by poor governance (WDR 2008, 245).

"The impacts of climate change are not evenly distributed - the poorest countries and people will suffer earliest and most....First, developing regions are at a geographic disadvantage: they are already warmer, on average, than developed regions, and they also suffer from high rainfall variability. ...Second, developing countries - in particular the poorest - are heavily dependent on agriculture, the most climate-sensitive of all economic sectors, and suffer from inadequate health provision and low-quality public services. Third, their low incomes and vulnerabilities make adaptation to climate change particularly difficult. ...At a national level, climate change will cut revenues and raise spending needs, worsening public finances." (Stern 2006, vii)

Modeling the effects of climate change is subject to considerable uncertainty, but there is consensus on its broad effects, some of which are summarized below.

(a) Food and Water: Global warming will reduce crop outputs at lower latitudes, undermining food security in the developing countries. If temperatures rise further, global food output will decrease, ${ }^{5}$ reducing the developing world's access to imported food.

Approximately one-third of the world's population lives in countries with moderate to high water stress (Stern 2006, 63), often exacerbated by poor management of water resources (World Bank 2007, 183). Rising demand for agriculture and other purposes will heighten water scarcity.

Climate change is also expected to disrupt rainfall patterns, threatening agricultural cycles and human lives with droughts and floods. These changes will 
impact the poorest billion people in the world most heavily because $75 \%$ of these people live in rural areas and rely on agriculture for their livelihood (Stern 2006, 67).

(b) Health and Human Capital: Climate change is increasing morbidity and mortality from vector-borne ${ }^{6}$ and diarrheal diseases, as well as malnutrition, and children are the most affected (McMichael et al. 2004). This situation can have lasting consequences for human capital. A study in Zimbabwe found that young children who became stunted as a result of a drought faced long-term negative effects in school attainment and subsequent earnings (Alderman et al. 2006).

(c) Natural Disasters: The frequency and severity of natural disasters is expected to increase, affecting and even displacing large numbers of people. Low-lying coastal areas will become increasingly uninhabitable and subject to flooding and hurricanes. Sea-level rise will bring salinization, salt-water intrusion in groundwater aquifers, and, in some areas, complete inundation (WDR 2008, 200).

Many countries in the most affected regions have poor preventive health systems, with a low capacity for averting and controlling disease outbreaks even during routine conditions. This capacity becomes especially critical in the face of natural disasters, with their attendant health threats (Das Gupta et al. 2009).

(d) Conflicts: The pace of internal and international migration will rise with the combined pressures of climate change, population growth, and environmental degradation (Laczko and Aghazarm 2009; World Bank 2010; Gemenne 2011), and migrants may not always be welcomed by people who may themselves feel under pressure. Migration from Bangladesh into parts of Northeast India has led to low-level conflict for decades, which could be exacerbated if the densely populated megadeltas of the Bay of Bengal are inundated by sea-level rise. Land degradation and drought have already caused considerable movement of people in sub-Saharan Africa. Mamdani (2001) notes that one of the factors underlying the Rwanda genocide was local resentment of the heavy in-migration of people seeking richer land.

\section{How Do The Poorest Countries Gain From Fertility Reduction?}

Fertility remains high in several developing countries, typically in the poorest ones. The least developed countries have an estimated average of 4.2 children per woman in 2010-5 (UN 2013, medium variant). The estimate for Sub-Saharan Africa is 5.1 children per woman in 2010-5, and the region's population is projected to rise from 0.64 to 3.82 billion between 2000 and 2100 (UN 2013, medium variant). Total fertility rates also remain high in a scattering of other developing countries. 
They remain above 3 children per woman in some larger Asian countries, such as the Philippines and Pakistan (UN 2013), and some of the least developed states of Northern India (Haub 2011, Figure 11).

Reducing fertility can benefit these countries in many ways, facilitating economic growth and poverty reduction. A large body of literature since the 1990s has discussed the "demographic dividend" that is enabled when fertility declines in high fertility settings. The resultant low dependency ratios create a window of opportunity for savings, increased productivity, and investment (Higgins and Williamson 1997; Kelley and Schmidt 1996, 2005). Some of this dividend is automatic, arising simply from increasing the resources per capita for services, infrastructure, and livelihoods. However, with good policy management and investment in physical and human capital, this window of opportunity can be used to transform economies such that their growth potential remains high after the window has closed. This is evidenced especially in East Asia (Bloom and Williamson 1998; Lee 2009). The more rapid a region's fertility decline, the wider the window of opportunity, although its duration will be shorter because the population will age more rapidly. ${ }^{7}$

This literature on the "demographic dividend" is sometimes interpreted as implying that fertility decline is "wasted" without strong policy settings such as those in East Asia. Yet, these studies emerged decades after vigorous family-planning programs were started in most Asian countries in the 1960s and 1970s. These programs were explicitly motivated by widespread poverty compounded by sharply rising population growth rates and were viewed as an integral part of the countries' development strategy. ${ }^{8}$ Reducing fertility helps to reduce poverty, as evidenced in India, where it mitigates some of the negative fallout of weak economic policies and slow job growth.

Micro-studies find that lower fertility helps to reduce poverty at the household level in developing countries. It has been found to be associated with better child health and schooling (Rosenzweig and Wolpin 1980; Rosenzweig and Zhang 2009), improved maternal health, increased women's labor force participation, and higher household earnings (Joshi and Schultz 2007). Young women have benefited especially from access to the family-planning program in Colombia, obtaining more schooling and increasing their likelihood of working in the formal sector (Miller 2010). Similar results have emerged from studies conducted in developed countries, as discussed below. Miller $(2010,711)$ concluded that family planning may be "among the most effective (and cost-effective) interventions to foster human capital accumulation". 9

These benefits are especially critical given the shortage of land and jobs in these countries, which leaves their growing populations ever more squeezed for livelihoods. Land scarcity is acute in most Asian countries, and in sub-Saharan Africa available cropland per agricultural person decreased by 40\% between 1960 and 2003 (World Bank 2007, 63). Although some sub-Saharan African countries have 
considerable room for land expansion, high rural population growth drives expansion into forest or grazing land. Large investments in infrastructure, disease control, and soil management are needed to convert these lands to productive agriculture (World Bank 2007, 63). Food production per capita changed little in sub-Saharan Africa between 1961 and 2005 (Figure 2).

There is also a shortage of jobs. Levels of unemployment are already high in many countries, but the World Bank $(2012,51)$ estimates that substantial job creation is required just to maintain the 2005 levels of employment of the working age population in 2020. For example, an additional million jobs a month will need to be generated in South Asia. Given the slow pace of job growth in this region, it is fortunate that the population aged 0-14 is projected to decline soon (UN 2013, medium variant), as also observed in India (Figure 3). The report also estimates that the number of jobs in sub-Saharan Africa would have to increase by about $50 \%$, which translates into employment growth of $2.7 \%$ a year. Meanwhile, the population aged 0-14 is growing rapidly in sub-Saharan Africa, and the numbers of people entering working age will continue to rise sharply for decades (Figure 3). The rapid projected growth of the young population in the least developed countries contrasts sharply with that of other developing countries (Figure 3), so countries with weak economic growth face the highest increase in numbers entering the labor force.

Population growth imposes a direct burden of resource depletion upon developing countries. Arrow et al. $(2004,164-5)$ estimate that the rate of depletion of

Figure 2. Changes in Food Production Per Capita, 1961-2005

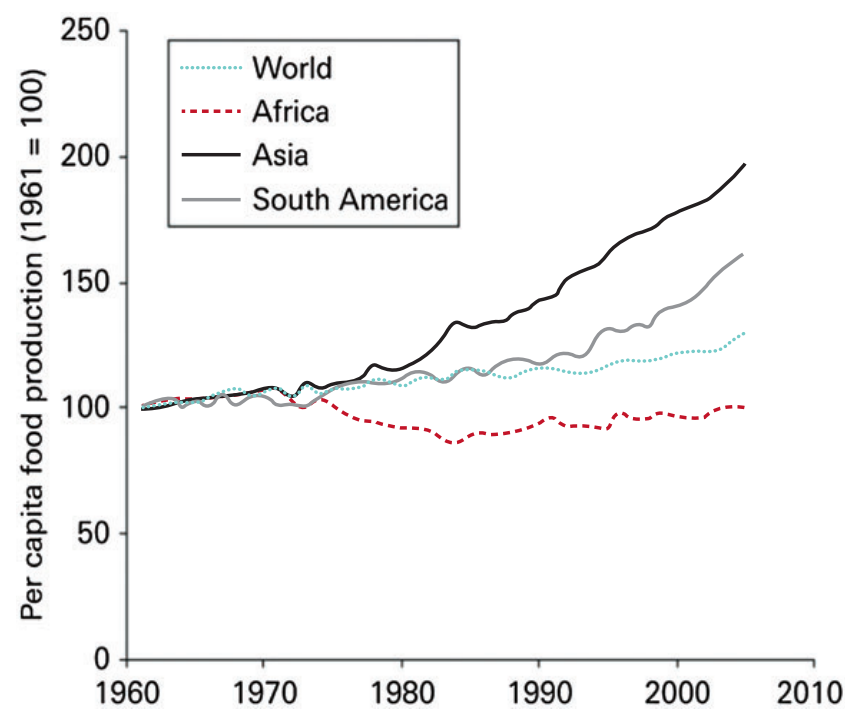

Source: The Royal Society 2009: Figure 1.4. 
Figure 3. Projected Labor-force Growth in Poorer Countries Compared with Other Developing Countries

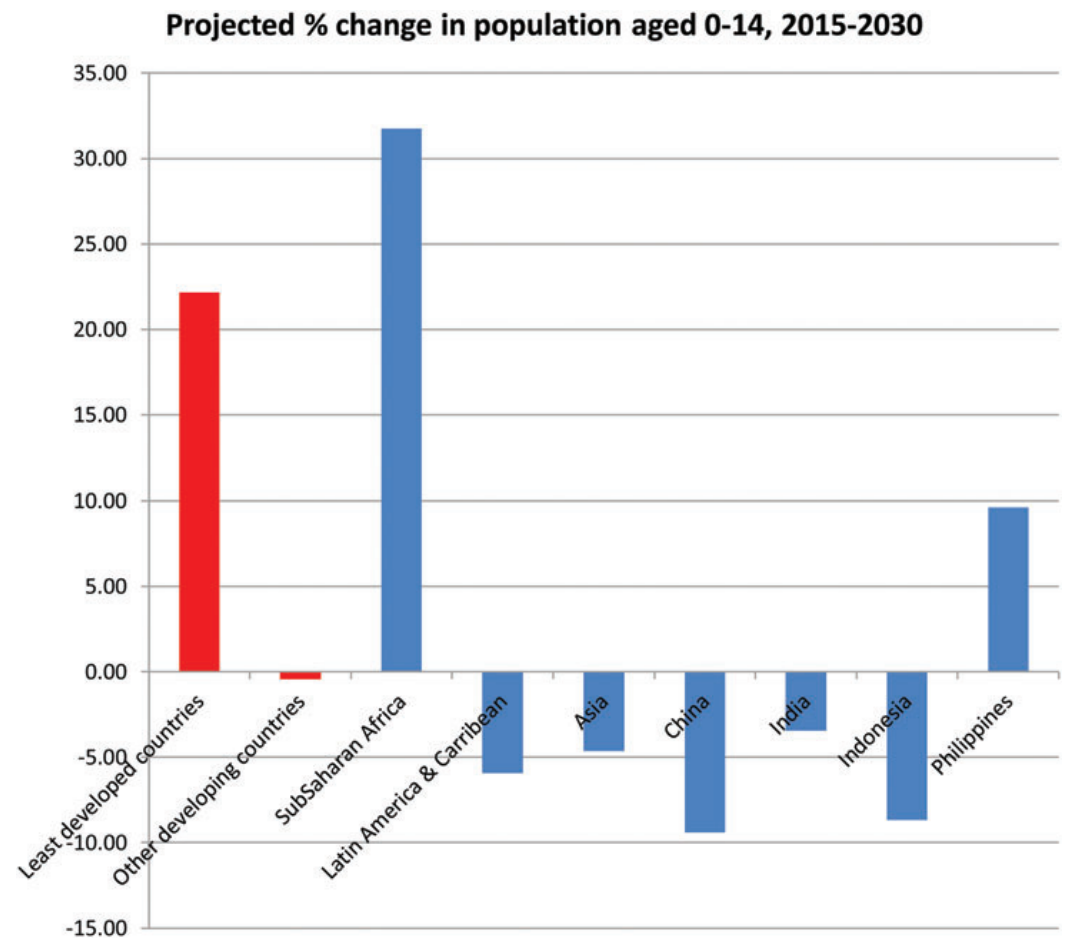

Source: United Nations (2013), medium variant.

"genuine wealth per capita" in sub-Saharan Africa during 1970-2000 was such that it would be halved about every 25 years. Kelley and Schmidt (2005) conclude that sub-Saharan Africa has benefited far less than have other regions from the impact of reduced dependency ratios on output growth per capita, because of its high fertility.

Lower fertility can also help the poorest countries' efforts to mitigate the effects of climate change so that the shocks affect fewer people, and more resources per capita are available for coping with them. These resources can be used for adaptation measures, such as efforts to slow the decline in food production. Systems for disaster management and preventive health services can be strengthened to minimize the spread of existing and emerging diseases. Such measures will make it easier to coordinate collective efforts to cope with climate change.

With less pressure on livelihoods, poor households will also be better positioned to cope with the consequences of climate change. Looking to the future, slower 
population growth will reduce these countries' projected contribution to future climate change, which will, as before, have the most devastating impact on these countries.

\section{Can Family-Planning Programs Help Lower Fertility?}

Government programs to promote the use of effective contraceptive methods are by no means a necessary condition of fertility decline; birth rates fell in Europe with no state encouragement. Nor are they the only policy levers to encourage lower fertility. Female education has been found to be associated with a higher age at first birth and lower fertility in settings as varied as Guatemala, Indonesia, and Nigeria. ${ }^{10}$ The key question is whether family- planning programs can advance the timing of reproductive change and accelerate it once it is underway.

In a highly influential paper, Pritchett (1994a) argued that family-planning programs have little impact on fertility: "Ninety percent of the differences across countries in total fertility rates are accounted for solely by differences in women's reported desired fertility.... The results contradict theories that assert a large causal role for expansion of contraceptive use in the reductions of fertility".

Many have taken Pritchett's study to indicate that effort on family-planning programs is ill spent. However, in a subsequent paper he concludes that his estimates imply that strengthening a family-planning program substantially (by 50 points on of a scale of 0-100) would reduce fertility by one birth (Pritchett 1994b, 626). Bongaarts (1997) estimates the corresponding fertility reduction at 1.4 births, but even Pritchett's lower estimate amounts to a very large difference in population size and in the momentum of population growth. If one less birth per woman were sustained in sub-Saharan Africa through 2100 , the region would have an estimated 2.6 billion fewer people. This would more than halve the estimated total population at the end of this century (Figure 4).

A crucial gap in Pritchett's argument is that he assumes that family planning programs work only on the supply side and overlooks their important role in reducing desired family size. He conducts cross-country regressions of total fertility rates against contraceptive prevalence and against family-planning efforts, but in both cases, he controls for desired fertility (Pritchett 1994a, Table 3). However, massmedia outreach to reduce desired family size is a major component of family-planning programs. Studies have shown that the mass media are very effective at increasing contraceptive use and reducing fertility (see below).

\section{What Do Family-Planning Programs Seek to Do?}

Family-planning programs seek to boost the use of contraceptive methods by expanding their supply and accessibility and disseminating information on the methods available, thus enabling couples to postpone or limit childbearing. This is 
Figure 4. Population Projections for Sub-Saharan Africa Indicate that Maintaining One Less Birth per Woman Halves the Estimated Population in 2100

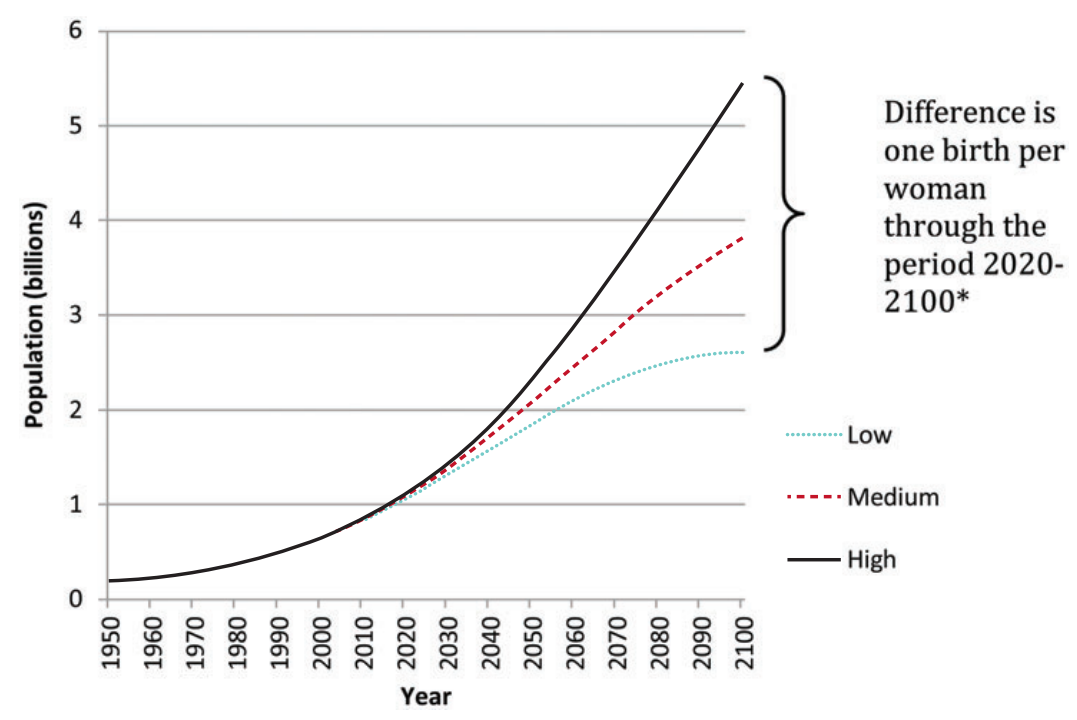

Source: United Nations (2013).

* The UN "high" and "low" projections diverge during 2010-2020, reaching a difference of 1 birth by 2020.

especially important for the poor, who typically have higher numbers of unwanted children than the rich, except in settings with very effective programs, such as Indonesia (Figure 5).

Family-planning programs also typically seek to reduce desired family size by disseminating information on new opportunities for altering living standards through new strategies for bearing and investing in children. Parents - especially poorer parents - have imperfect information on these issues. Households also appear to face difficulties in making optimal choices that involve long-term planning horizons (see, for example, Cronqvist and Thaler 2004 on pension decisions). People's access to information can be improved by offering simple messages through mass communication or more complex messages through radio or television soap operas that portray the lives of people with small families and how they access new opportunities helps reduce imperfect information.

Media outreach has been found to be effective at increasing contraceptive use and lowering fertility. This has been found in many studies using cross-sectional survey data on access to media (e.g., Bhat 1998). The few quasi-randomized evaluations of media outreach have found it effective at altering fertility and contraceptive 
Figure 5. Unwanted Fertility is Higher among the Poor, and Effective Family-Planning Programs Can Reduce this Gap

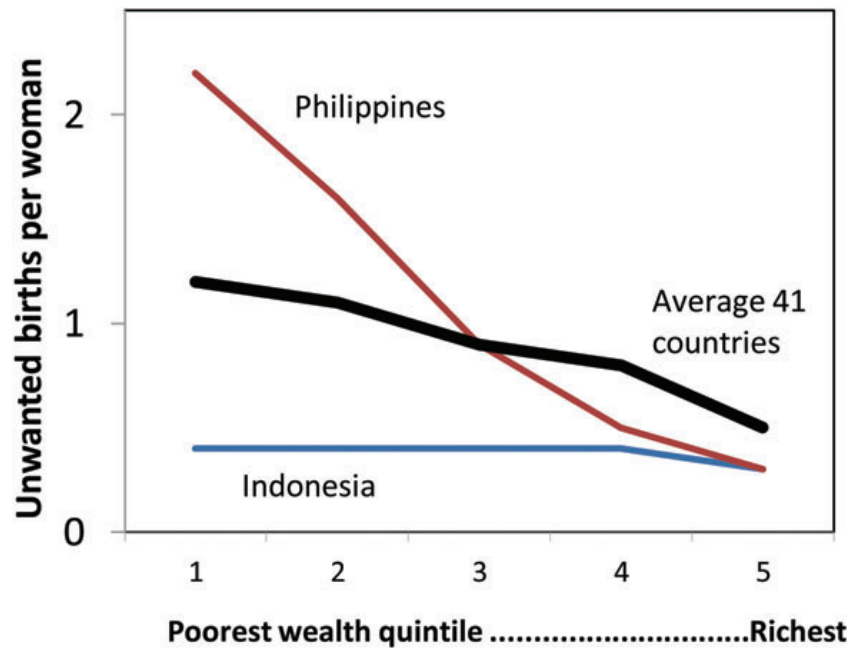

Source: Gillespie et al. (2007), Table 1.

use in Tanzania (Rogers et al. 1999) and reducing fertility in Brazil and India (La Ferrara et al. 2008; Jensen and Oster 2009).

To motivate their evaluation of the impact of Brazilian soap operas on fertility, La Ferrara et al. $(2008,9)$ report the results of an experimental focus-group discussion in which adult women of middle- and lower-class backgrounds were asked to portray the families that are frequently displayed on television as well as those of common people. "The results were clear: television families are small, rich and happy; the families portrayed as common people are poor, contain more children and the faces reveal unhappiness. ...constant exposure to smaller, less- burdened television families may have created a preference for fewer children and greater sensitivity to the opportunity costs of raising children".

This is exactly the approach used in many countries, such as South Korea and India, using simple billboards. Their family-planning programs catalyzed demand through media blitzes that conveyed images of glowing parents with one or two flourishing children, sometimes juxtaposed with images of overwhelmed parents surrounded by many children living in much poorer conditions. Brief jingles on the radio and television reinforced the message that "a small family is a happy family".

Such media blitzes are especially important in settings where contraceptive use is not yet commonplace. By reaching entire communities, they help to change social norms and reduce barriers to the use of contraceptives. One barrier may be that women are more motivated than men to control childbearing. For example, a study 
in Zambia found that women who were given contraceptive information and access without their husbands present were more likely to use contraception and less likely to give birth than a control group of women accompanied by their husbands (Ashraf et al. 2012). Another such barrier is suggested by a study in urban slums in Pakistan, which found that mothers-in-law influenced contraceptive decisionmaking (Fikree et al. 2001). Studies in several countries show that women resort to the covert use of contraception, when their use is not generally accepted. By helping shift social norms, media outreach helps empower women to use contraception.

\section{Evaluations of Family-Planning Programs}

Evaluating the impact of family-planning programs is challenging because these programs are rarely randomly placed and uniformly executed. However, studies using very different analytical approaches, including natural experiments, indicate that family-planning programs do affect fertility.

Schultz $(2009,4)$ notes that several careful evaluations of family-planning programs find a negative association between "the regional intensity of program treatment and the regional level of fertility" in a country. These include studies of programs in Taiwan (Schultz 1973, 1992), Colombia (Rosenzweig and Schultz 1982), and Indonesia (Molyneaux and Gertler 1994). Some studies are simple cross-sectional analyses, but others have gone further to analyze panel data and include fixed effects for regions and time. However, the estimated program impact may be biased by nonrandom placement.

Several studies use natural experiments or quasi-randomized trials. In the Matlab program in Bangladesh, half of the villages studied for the 1974-96 period received more intensive family planning and maternal and child health program inputs from 1977-8, whereas the other half received regular government program inputs. Note that the country was poor and largely illiterate for much of the study period. The first set of villages showed more rapid fertility decline after the program began and maintained 15\% lower fertility in 1982-96 (Joshi and Schultz 2007, 30). Sinha (2005) found that 18 years after the Matlab program began, it accounted for a $14 \%$ decline in lifetime fertility ( 0.6 fewer births per woman) compared with women in the second set of villages. This difference is especially striking given that fertility was falling rapidly across the country. If sustained over time, this difference in fertility can considerably reduce the momentum of population growth, as the difference between the UN projection variants show (Figure 4).

Miller (2010) evaluated Colombia's family-planning program, exploiting differences in the timing of the introduction of the family-planning program to estimate the impact of contraceptive availability on fertility. The program was found to have lowered fertility by about $10 \%$, despite the fact that fertility was declining rapidly 
across the country. Households with lower fertility also showed improvements in schooling, health, and earnings. Miller noted that access to family planning helped young women obtain more schooling and increased their chances of working in the formal sector.

These evaluations may tend to underestimate the impact of family-planning programs insofar as their measures of program effort are more likely to pick up variation on the supply side. Mass communication efforts to reduce desired family size are likely to reach people regardless of whether they live in areas with higher or lower supply-side program effort.

Some recent studies have used natural experiments that were created by policyrelated variations in access to family planning to examine the impact of access to contraceptives. These studies indicate that facilitating access to contraception is highly pro-poor, as indicated by Figure 5. Two studies examine the impact of shifts in the application of the United States' "gag rule" (Mexico City Policy), which restricts foreign aid for family planning to any organization that may provide abortions using other funds. Jones (2011) estimated that the policy was associated with a $12 \%$ increase in pregnancies among rural women in Ghana, increasing both abortions and unintended births. The unintended births were concentrated among the poorest and least educated women, and these children had significantly lower height-for-age relative to their siblings. Bendavid et al. (2011) found that after the Mexico City Policy was reinstated in 2001, abortion rates rose in sub-Saharan African countries that receive high levels of foreign assistance from the United States for family planning and reproductive health. Salas (2013) found that policyrelated disruptions in the public supply of free contraceptives in the Philippines was associated with elevated birth rates, especially among poor, less educated, and rural women.

Similar findings emerge from the analyses of natural experiments in the developed world. Kearney and Levine (2009) examined the impact of state-level Medicaid policy changes in the United States that expanded eligibility for familyplanning services and found that it reduced births, particularly for teenagers and those with lower educational attainment. Bailey (2012) estimated that federally funded family planning in the United States reduced childbearing among poor women by $19 \%$ to $30 \%$ between 1964 and 1973. Reflecting the findings in Bangladesh and Colombia discussed above, analyses of natural experiments in the United States and Sweden have found significant female labor supply responses to differences in the provision of the birth control pill (Goldin and Katz 2002; Ragan 2013).

Jones' (2011) finding that unintended children in Ghana were more likely to be stunted than their siblings is consistent with other studies that indicate that greater investments are made in planned children. For example, Do and Phung (2010) used the fact that in Vietnam, some years in the animal zodiac cycle are considered 
especially auspicious to bear children. They found that larger cohorts of children are born in auspicious years and that these children have higher schooling attainment. They concluded that this is because parents are more likely to invest in planned children. Analyses of natural experiments in the United States and Sweden indicate that increasing women's ability to plan their births was associated with substantial improvements in their children's education and earning capacity (Rotz 2013, Madestam and Simeonova 2013).

\section{Are Family-Planning Programs Likely to Work in the Poorest Countries?}

The experience of countries such as the Republic of Korea in the 1960s and others such as Indonesia, Bangladesh, or Nepal shows that sustained fertility decline can occur in poor countries given political commitment to family-planning programs. This commitment is driven by poverty and sharply rising population growth rates. For example, India's censuses showed decadal growth of $11 \%-14 \%$ from the 1920 s, but this jumped to $22 \%$ in 1951-61 and 25\% during 1961-71. Similar population growth rates were observed in the Asian region and sub-Saharan Africa (UN 2013). However, sub-Saharan Africa's small population base in the 1950 s meant low increases in numbers, a situation that is changing very quickly (Figure 4).

Political commitment to family planning has sometimes been low in many subSaharan African countries, which may have contributed to their slow fertility decline (Cleland et al. 2006, 2011; Bongaarts 2006; Machiyama 2010). ${ }^{11}$ However, this situation can change quickly, as evidenced by the success of the Rwandan government's concerted push since the mid-2000s to reduce fertility. Until then, both Rwanda and its neighbor, Burundi, were poor, densely populated countries with high fertility and weak family-planning programs. Then, in contrast with Burundi, Rwandan government officials spoke out about the need to reduce fertility. A country-wide information dissemination program was implemented, along with sharply increased access to contraceptive methods. Between the DHS surveys of 2005 and 2010, the total fertility rate fell from 6.1 to 4.6 children per woman, and the use of modern methods of contraception among married women rose from $10 \%$ to $45 \%$ (National Institute of Statistics of Rwanda 2011). Meanwhile, total fertility in Burundi was 6.4 in 2010 (Institut de Statistiques et d'Études Économiques du Burundi 2010).

Most countries in sub-Saharan Africa show some fertility decline, indicating a desire to lower fertility. Family-planning programs can build on this desire and accelerate fertility decline. These programs are likely to be most effective when accompanied by other measures addressing basic government failures that help sustain poverty and high fertility, including efforts to improve health and schooling and to expand income-earning opportunities. Family-planning programs help by increasing access to contraception and by providing informational outreach to accelerate 
perception of the benefits of shifting to a more secure equilibrium in which people have fewer children and are able to invest more in them.

\section{Conclusions}

The management of environmental common property resources is complex because these resources are unpriced, so people must agree to self-impose a price for using them. Their over-exploitation by countries that began industrializing early has led to global warming. The fallout of this will, in an ironic twist of fate, fall primarily on the developing countries, many of which are still poor and have low percapita emissions. These countries will be the first to experience declines in agricultural output, poorer health outcomes, disruption of rainfall patterns, and more frequent and severe natural disasters, which render some areas uninhabitable. These changes make it harder for poor people to emerge from poverty, and they push others into poverty.

However, although per-capita emissions in developed countries remain much higher than those in developing countries, their growth seems to have peaked. Most of the projected growth in emissions derives from the developing countries, due to their economic growth and their population growth. Most future population growth is projected to take place in these countries, with the highest growth rates in sub-Saharan Africa and the least developed countries.

In this highly complex situation, analysts have focused on policies to reduce greenhouse gas emissions. A carbon tax is proposed as the simplest approach to reduce carbon emissions. By putting a price on carbon emissions, such a tax creates incentives to conserve their use while providing incentives and fiscal resources for developing cleaner technologies. Some have argued that pricing carbon use could be introduced more gradually in developing countries to impose less constraint on their potential economic growth.

Neglected in these policy debates is the fact that a substantial part of future growth in emissions derives from population growth, mostly in the poorest countries. Although population size is incorporated into models of climate change, the population projections are taken as a given. However, fertility is highly amenable to policy intervention. For countries that still have high fertility and that typically have very low per-capita emission levels at present because they are still poor, the more immediate approach might be to lower fertility.

Clearly, the poorest countries cannot be expected to reduce fertility to help the world as a whole, especially when they are suffering from the excesses perpetrated by the rest of the world. However, they have much to gain from lowering fertility. It will increase their available resources per capita, enabling them to invest more in the human and physical capital needed for economic growth. It will also increase 
per-capita resources to strengthen systems for disaster management and for disease prevention and control, helping them to cope more effectively with the multiplicity of stresses associated with climate change. It will reduce growth in the demand for jobs and livelihoods. Moreover, studies from both developing and developed countries show that access to birth planning helps reduce poverty through increased female labor force participation and better child schooling and health outcomes. Furthermore, fertility decline in poor countries yields a substantial "demographic dividend" in reducing poverty and vulnerability, even without the large additional gains that can be obtained with strong economic policies.

Lower fertility will also benefit the poorest countries by reducing the pace of future global warming, the negative effects of which affect them far more than developed countries. The latter countries mostly lie at geographically higher latitudes that are less negatively affected by climate change. Furthermore, the developed countries have far greater resources to cope with climate change.

The means of lowering fertility are well documented. Family-planning programs help by increasing access to contraception and by catalyzing demand for contraception through media blitzes. Studies show that family-planning programs are effective at helping to lower fertility, and highly pro-poor in their impact. Easier access to family-planning most benefits women who are poor and uneducated. Family-planning programs are a simple, effective, and relatively inexpensive way to achieve a multiplicity of benefits for poor countries.

While the rest of the world wrestles with the political and technological complexities of reducing emissions, family-planning programs offer the poorest countries a simple and effective means to reduce poverty and mitigate the impact of climate change.

\section{Notes}

Research Professor, Department of Sociology, University of Maryland, College Park, MD and Visiting Fellow, Population Reference Bureau, Washington, DC. Email: mdasgupta@gmail.com. This work was supported by the William and Flora Hewlett Foundation [Trust Fund TF070424 to the World Bank and grant number 2012-7611 to the Population Reference Bureau]. Comments from Emmanuel Jimenez and an anonymous reviewer were very helpful for revising the draft, all errors remain mine.

1. Simon and Boserup both argued that higher population densities can increase the economies of scale in providing productivity-enhancing infrastructure and services, such as transport and extension services (Glover and Simon 1975; Boserup 1981).

2. See also Lee and Miller (1990).

3. United States Environmental Protection Agency (nd) Global Greenhouse Gas Emissions Data http://www.epa.gov/climatechange/ghgemissions/global.html (accessed 5 June 2013).

4. Many have estimated that slowing population growth could substantially reduce carbon emissions (see, for example, Meadows et al. 1972; Bongaarts 1992; and O’Neill et al. 2010).

5. World Bank 2007, 200; FAO 2009, 29; Stern 2006, 67; Potsdam Institute 2012. 
6. For example, PAHO has estimated that the incidence of dengue, another vector-borne disease, has risen in the temperate as well as the tropical zones of the Americas.

7. Other macro-studies indicate that rapid population growth can constrain economic growth (Galor and Weil 2000; Weil and Wilde 2009) and reduce growth in income per capita (Acemoglu and Johnson 2007). For reviews of studies of the relationship between population and economic growth, see Johnson and Lee (1986); Kelly (1988); and Das Gupta et al. (2011).

8. See, for example, Jones (1982) on Vietnam, Das Gupta (1995) on India and the official presentation of the South Korean family planning program at the IUSSP General Population Conference, Busan August 2013.

9. Some studies in the developed world also find high fertility is negatively associated with child schooling and female labor-force participation (Black et al. 2005; Caceres-Delpiano 2006; Angrist and Evans 1998; Conley and Glauber 2006). Other studies do not find evidence of a quantity-quality trade-off in childbearing (Angrist et al. 2010).

10. Behrman et al. 2006; Breierova and Duflo 2004; Osili and Long 2008.

11. Zimbabwe offers an example of rapid fertility decline with strong political will, but it was not a poor country at the time.

\section{References}

Acemoglu, D., and S. Johnson. 2007. "Disease and Development: The Effect of Life Expectancy on Economic Growth.” Journal of Political Economy, 115 (6): 925-85.

Alderman, H., J. Hoddinott, and B. Kinsey. 2006. "Long Term Consequences of Early Childhood Malnutrition." Oxford Economic Papers 58 (3): 450-74.

Angrist, J.D., and W.N. Evans. 1998. "Children's and Their Parents' Labor supply: Evidence from Exogenous Variation in Family Size." American Economic Review 88 (3): 450-77.

Angrist, J.D., V. Lavy, and A. Schlosser. 2010. "Multiple Experiments for the Causal Link between the Quantity and Quality of Children." Journal of Labor Economics 28 (4): 773-824.

Arrow, K.J. 1969. "The Organization of Economic Activity: Issues Pertinent to the Choice of Market versus Non-market Allocations", Washington, DC: Joint Economic Committee of Congress.

Arrow, K., P. Dasgupta, L. Goulder, G. Daily, P. Ehrlich, G. Heal, S. Levin, M. Karl-Göran, S. Schneider, D. Starrett, and B. Walker. 2004. "Are We Consuming Too Much?" Journal of Economic Perspectives, 18 (3): $147-72$.

Ashraf, N., E. Field, and J. Lee. 2012. "Household Bargaining and Excess Fertility: An Experimental Study in Zambia." Working Paper, Harvard University, Cambridge.

Bailey, M.J. 2012. "Re-examining the Impact of Family Planning Programs on US Fertility: Evidence from the War on Poverty and the Early Years of Title X." American Economic Journal: Applied Economics 4 (2): 62-97.

Barnett, H.J., and C. Morse. 1963. Scarcity and growth: the economics of natural resource availability. Baltimore: Johns Hopkins Press.

Behrman, J.R., A. Murphy, A. Quisumbing, U. Ramakrishnan, and K. Yount. 2006. "What is the real impact of schooling on age of first union and age of first parenting? New evidence from Guatemala.” Policy Research Working Paper 4023, World Bank, Washington DC.

Bendavid, E., P. Avila, and G. Miller. 2011. United States Aid Policy and Induced Abortion in SubSaharan Africa. Bulletin of the World Health Organization. Published online October 14, 2011. http ://www.who.int/bulletin/11-091660.pdf. 
Bhat, P., and N. Mari. 1998. "Emerging Regional Differences in Fertility in India: Causes and Correlations." In Reproductive Change in India and Brazil, eds. G. Martine, M.D. Gupta, and L.C. Chen, 131-68. New Delhi: Oxford University Press.

Black, S., P.J. Devereux, and K. Salvanes. 2005. "The More the Merrier? The effect of family size and birth order on children's education.” The Quarterly Journal of Economics 120 (2): 669-700.

Bloom, D.E., and J.G. Williamson. 1998. "Demographic Transitions and Economic Miracles in Emerging Asia." World Bank Economic Review 12 (3): 419-55.

Bongaarts, J. 1992. "Population Growth and Global Warming." Population and Development Review 18 (2): $299-319$.

. 1997. "The role of family planning programs in contemporary fertility transitions." In The Continuing Demographic Transition, eds. G.W. Jones, R.M. Douglas, J.C. Caldwell, and R.M. D'Souza, 422-44. Oxford: Clarendon Press.

2006. "The causes of stalling fertility transitions." Studies in Family Planning 39:105-10.

Boserup, E. 1965. The Conditions of Agricultural Growth: The Economics of Agrarian Change under Population Pressure. Chicago: Aldine.

1981. Population and Technological Change: A Study of Long-Term Trends. Chicago: University of Chicago Press.

Breierova, L., and E. Duflo. 2004. "The Impact of Education on Fertility and Child Mortality: Do Fathers Really Matter Less Than Mothers?” NBER Working Paper 10513, National Bureau of Economic Research, Cambridge, MA.

Caceres-Delpiano, J. 2006. “The Impacts of Family Size on Investment in Child Quality.” Journal of Human Resources 41 (4): 738-54.

Cleland, J., S. Bernstein, A. Ezeh, A. Faundes, A. Glasier, and J. Innis. 2006. "Family planning: the unfinished agenda." The Lancet 368 (9549): 1810-27.

Cleland, J., R.P. Ndugwa, and E.M. Zulu. 2011. "Family planning in sub-Saharan Africa; progress or stagnation?" Bulletin of the World Health Organization 89:137-43.

Conley, D., and R. Glauber. 2006. "Parental Educational Investment and Children's Academic Risk: Estimates of the Impact of Sibship Size and Birth Order from Exogenous Variation in Fertility." Journal of Human Resources 41 (4): 722-37.

Cronqvist, H., and R. Thaler. 2004. "Design choices in privatized social-security systems: Learning from the Swedish experience." American Economic Review 94 (2): 424-8.

Das Gupta, M. 1995. "Population and Development Policies and Programmes in India." In Development Patterns and Institutional Structures: China and India, eds. S.P. Gupta, N. Stern, and A. Hussain, 171-206. New Delhi: Allied Publishers.

Das Gupta, M., B.R. Desikachari, T.V. Somanathan, and P. Padmanaban. 2009. "How to improve public health systems: lessons from Tamil Nadu.” Policy Research Working Paper 5073, World Bank, Washington DC.

Das Gupta, M., J. Bongaarts, and J. Cleland. 2011. "Population, Poverty, and Sustainable Development: a review of the evidence." Policy Research Working Paper 5719, World Bank, Washington DC.

Dasgupta, P., K. Mäler, and A. Vercelli (eds). 1997. The Economics of Transnational Commons. Oxford: Clarendon Press.

Dasgupta, P. 2001. Human Well-Being and the Natural Environment. Oxford: Oxford University Press.

. 2010. "Nature's role in sustaining economic development." Philosophical Transactions of the Royal Society 365 (1537): 5-11.

Diaz, R.J., and R. Rosenberg. 2008. "Spreading Dead Zones and Consequences for Marine Ecosystems." Science 321:926-8. 
Do, Q.-T., and T.D. Phung. 2010. “The Importance of Being Wanted.” American Economic Journal: Applied Economics 2 (4): 236-53.

Dyson, T. 2005. "On development, demography and climate change: the end of the world as we know it?" Population and Environment 27 (2): 117-49.

FAO 2009. How to feed the world in 2050. Rome: Food and Agriculture Organization of the United Nations.

Fikree, F.F., A. Khan, M.M. Kadir, E. Sajan, and M.H. Rahbar. 2001. "What Influences Contraceptive Use Among Young Women In Urban Squatter Settlements of Karachi, Pakistan?” International Family Planning Perspectives 27 (3): 130-6.

Galor, O., and D. Weil. 2000. "Population, Technology, and Growth: From Malthusian Stagnation to the Demographic Transition and Beyond." American Economic Review, 90 (4): 806-28.

Gemenne, F. 2011. "Climate-induced population displacements in a $4^{\circ} \mathrm{C}+$ world." Philosopical Transactions of the Royal Society 369 (1934): 182-95.

Gillespie, D., S. Ahmed, A. Tsui, and S. Radloff. 2007. "Unwanted fertility among the poor: an inequity?" Bulletin of the World Health Organization 85 (2): 100-7.

Glover, D.R., and J.L. Simon. 1975. "The Effect of Population Density Upon Infrastructure: The Case of Road Building." Economic Development and Cultural Change 23 (3): 453-68.

Goldin, C., and L. Katz. 2002. "The Power of the Pill: Oral Contraceptives and Women's Career and Marriage Decisions." Journal of Political Economy 110 (4): 730-70.

Haub, C. 2011. Future fertility prospects for India. New York: United Nations Population Division Expert Paper No. 2011/4.

Higgins, M., and J. Williamson. 1997. "Age Structure Dynamics in Asia and Dependence on Foreign Capital." Population and Development Review 23 (2): 261-93.

Institut de Statistiques et d'Études Économiques du Burundi. 2010. Enquête Démographique et de Santé Burundi 2010. Rapport Préliminaire, MEASURE DHS, ICF Macro, Calverton.

International Monetary Fund. 2010. World Economic Outlook Database April 2006 (accessed 15 December 2010) http://www.imf.org/external/pubs/ft/weo/2006/01/data/dbcselm.cfm?G=2001.

. 2011. World Economic Output Update, Washington DC: IMF http://www.imf.org/external/ pubs/ft/weo/2011/update/01/pdf/0111.pdf.

Intergovernmental Panel on Climate Change. 2007. Climate Change 2007: Impacts, Adaptation and Vulnerability. Contribution of Working Group II to the Fourth Assessment Report of the Intergovernmental Panel on Climate Change, eds. M.L. Parry, O.F. Canziani, J.P. Palutikof, P.J. van der LindenC.E. Hanson. Cambridge: Cambridge University Press.

Jensen, R., and E. Oster. 2009. “The Power of TV: Cable Television and Women's Status in India.” Quarterly Journal of Economics 124 (3): 1057-94.

Johnson, D.G., and R.D. Lee (eds). 1987. Population Growth and Economic Development: Issues and Evidence. US National Research Council Committee on Population, Working Group on Population Growth and Economic Development. Madison: The University of Wisconsin Press.

Jones, G.W. 1982. "Population Trends and Policies in Vietnam.” Population and Development Review 8 (4): $783-810$.

Jones, K. 2011. "Evaluating the Mexico City Policy: How US foreign policy affects fertility outcomes and child health in Ghana.” Discussion Paper 01147, International Food Policy Research Institute, Washintgon DC.

Joshi, S., and T.P. Schultz. 2007. "Family Planning an Investment in Development: Evaluation of a Program's Consequences in Matlab, Bangladesh.” Economic Growth Center Discussion Paper No. 951, Yale University, New Haven. 
Kearney, M.S., and P.B. Levine. 2009. "Subsidized Contraception, Fertility, and Sexual Behavior.” The Review of Economics and Statistics 91 (1): 137-51.

Kelley, A.C. 1988. "Economic Consequences of Population Change in the Third World." Journal of Economic Literature 26 (4): 1685-728.

Kelley, A.C., and R.M. Schmidt. 1996. "Saving, Dependency and Development.” Journal of Population Economics 9 (4): 365-86.

2005. "Evolution of recent economic-demographic modeling: A synthesis." Journal of Population Economics 18:275-300.

La Ferrara, E., A. Chong, and S. Duryea. 2008. "Soap Operas and Fertility: Evidence from Brazil." Bureau for Research and Economic Analysis of Development (BREAD) Working Paper No. 172, Duke University, Durham.

Laczko, F., and C. Aghazarm (eds). 2009. Migration, Environment and Climate Change: assessing the evidence. Geneva: International Organization for Migration.

Lee, R.D. 1990. "Comment: The Second Tragedy of the Commons." Population and Development Review 16 (Supplement): 315-22.

2009. "New Perspectives on Population Growth and Economic Development." Paper presented at the International Union for the Scientific Study of Population Conference, Marrakech, September 27 - October 2.

Lee, R.D., and T. Miller. 1990. "Population Policy and Externalities to Childbearing", Annals of the American Academy of Political and Social Science 510 (July): 17-32.

Lotze-Campen, H., A. Popp, J.P. Dietrich, and M. Krause. 2009. "Competition for land between food, bioenergy and conservation." Background Note to the World Development Report 2010, World Bank, Washington DC.

Machiyama, K. 2010. "A reexamination of recent fertility declines in sub-Saharan Africa." DHS Working Paper, ICF Macro, Calverton.

Mamdani, M. 2001. When Victims Become Killers: Colonialism, Nativism, and the Genocide in Rwanda. Princeton: Princeton University Press.

Madestam, A., and E. Simeonova. 2013. Children of the Pill: the effect of subsidizing oral contraceptives on children's health and wellbeing. Paper presented at the American Economic Association annual meeting, San Diego, January 4-6.

McMichael, A., D. Campbell-Lendrum, S. Kovats, S. Edwards, P. Wilkinson, T. Wilson, R. Nicholls, S. Hales, F. Tanser, D. LeSueur, M. Schlesinger, and N. Andronova. 2004. "Global climate change." In Comparative quantification of health risks: global and regional burden of disease due to selected major risk factors, eds. M. Ezzati, A. Lopez, A. Rodgers, and C. Murray, 1543-649. Geneva: World Health Organization.

Meadows, D.H., D.L. Meadows, J. Randers, and W.W. Behrens, III. 1972. The Limits to Growth. New York: Universe Books.

Miller, G. 2010. "Contraception as Development? New Evidence from Family Planning in Colombia.” Economic Journal 120 (545): 709-36.

Molyneaux, J.W., and P.J. Gertler. 2000. "The Impact of Targeted Family Planning Programs in Indonesia." Population and Development Review 26 (Supplement: Population and Economic Change in East Asia): 61-85.

National Institute of Statistics of Rwanda. 2011. Rwanda Demographic and Health Survey 2010. Preliminary Report, MEASURE DHS, ICF Macro, Calverton.

Nordhaus, W. 2008. A Question of Balance: Weighing the Options on Global Warming Policies. New Haven: Yale University Press. 
2012. "Economic aspects of global warming in a post-Copenhagen environment." Proceedings of the National Academy of Sciences 107 (26): 11721-6.

Osili, U.O., and B.T. Long. 2008. "Does Female Schooling Reduce Fertility? Evidence from Nigeria." Journal of Development Economics 87 (1): 57-75.

O'Neill, B.C., M. Dalton, R. Fuchs, L. Jiang, S. Pachauri, and K. Zigova. 2010. "Global demographic trends and future carbon emissions." Proceedings of the National Academy of Sciences 107 (41): $17521-6$.

Ostrom, E. 1990. Governing the commons: The evolution of institutions for collective action. Cambridge: Cambridge University Press.

Potsdam Institute. 2012. Turn Down the Heat: Why a $4^{\circ} \mathrm{C}$ Warmer World Must Be Avoided. A Report for the World Bank by the Potsdam Institute for Climate Impact Research and Climate Analytics. Washington DC: The World Bank.

Potter, N., and F.T. Christy, Jr. 1962. Trends in Natural Resource Commodities, Baltimore: Johns Hopkins University Press.

Pritchett, L.H. 1994a. "Desired Fertility and the Impact of Population Policies." Population and Development Review 20 (1): 1-55.

1994b. “The Impact of Population Policies: Reply." Population and Development Review 20 (3): 621-30.

Ragan, K. 2013. "How Powerful Was the Pill? Quantifying a Contraceptive Technology Shock." Paper presented at the American Economic Association Annual Meeting, San Diego, January 4-6.

Rogers, E.M., P.W. Vaughan, R.M.A. Swalehe, N. Rao, P. Svenkerud, and S. Sood. 1999. "Effects of an Entertainment-education Radio Soap Opera on Family Planning Behavior in Tanzania." Studies in Family Planning 30 (3): 193-211.

Rosenzweig, M., and T.P. Schultz. 1982. "Child Mortality and Fertility in Colombia." Health Policy and Education 2:305-48.

Rosenzweig, M., and K.I. Wolpin. 1980. "Testing the Quantity-Quality Fertility Model: The Use of Twins as a Natural Experiment." Econometrica 48 (1): 227-40.

Rosenzweig, M.R., and J. Zhang. 2009. "Do Population Control Policies Induce More Human Capital Investment? Twins, Birth Weight and China's 'One-Child' Policy.” Review of Economic Studies 76 (3): $1149-74$.

Rotz, D. 2013. The Impact of Legal Abortion on the Wage Distribution: Evidence from the 1970 New York Abortion Reform. Paper presented at the American Economic Association annual meeting, San Diego, January 4-6.

The Royal Society. 2009. Reaping the Benefits: science and the sustainable intensification of global agriculture. London: The Royal Society.

Salas, J., and M. Ian. 2013. "Consequences of withdrawal: Free condoms and birth rates in the Philippines." Paper presented at the American Economic Association Annual Meeting, San Diego, January 4-6.

Schultz, T.P. 1973. "Explanations of Birth Rate Changes over Space and Time: a Study of Taiwan." Journal of Political Economy 81 (2): S238-74.

1992. "Assessing Family Planning Cost-Effectiveness.” In Family Planning Programs and Fertility, J.F. Phillips, and J.A. Press, eds, 78-105. New York: Oxford University Press.

—. 2009. "How Does Family Planning Promote Development?: Evidence from a Social Experiment in Matlab, Bangladesh, 1977 - 1996" (http://www.econ.yale.edu/ pschultz/ TPS_10_30_QJE.pdf).

Simon, J.L. 1981. The Ultimate Resource. Princeton: Princeton University Press. 
1996. The Ultimate Resource 2. Princeton: Princeton University Press.

Sinha, N. 2005. "Fertility, Child Work, and Schooling Consequences of Family Planning Programs: Evidence from an Experiment in Rural Bangladesh." Economic Development and Cultural Change 54 (1): $97-128$.

Stern, N. 2006. The Economics of Climate Change The Stern Review. Cambridge: Cambridge University Press.

Turner, G.M. 2008. "A Comparison of the Limits to Growth with Thirty Years of Reality." Sustainable Ecosystems Working Paper Series 2008-9, CSIRO, Canberra.

2012. "On the Cusp of Global Collapse? Updated Comparison of The Limits to Growth with Historical Data." GAIA 21/2: 116-24.

United Nations. 2013. World Population Prospects: The 2012 Revision. New York: United Nations.

Weil, D.N., and J. Wilde. 2009. "How Relevant Is Malthus for Economic Development Today?" American Economic Review 99 (2): 255-60.

World Bank. 2007. World Development Report 2008: Agriculture for Development. Washington DC: The World Bank. 2010. World Development Report 2010: Development and Climate Change. Washington DC: The World Bank. 2012. World Development Report 2013: Jobs. Washington DC: The World Bank. 